\title{
SEGURANÇA PÚBLICA NO BRASIL: REPASSES E INVESTIMENTOS PÚBLICOS E TAXAS DE HOMICÍDIOS
}

\begin{abstract}
RESUMO
A segurança pública se converteu em um dos principais temas da agenda pública social, inclusive a brasileira. Geralmente, as políticas de segurança ocorrem em interface com as políticas urbanas, portanto, vale alertar: os projetos governamentais relacionados à segurança, caso não sejam por meio de uma proposta de inclusão de todos, fracassarão. Relacionando com a Geografia, o tema ganhou repercussão dentro da chamada Geografia da Violência ou do Crime, na qual os estudos espacializam a base empírica e promovem reflexões pautadas nas questões sociais. Tratada com destaque na atual Constituição Federal, a segurança pública ainda carece de materialização dos projetos e das ações. Os repasses para os Estados acontecem, muitas vezes, por meio de interesses políticos e não fundamentados em indicadores ou necessidades. Por isso, observa-se Estados, como Alagoas e Sergipe, com repasses insignificantes e altíssimas taxas de homicídios. Em contrapartida, grandes receptores de verbas, São Paulo e Rio de Janeiro, são os que apresentam as maiores reduções nos homicídios, considerando os últimos anos.
\end{abstract}

Palavras-chave: Segurança pública. Geografia da Violência. Brasil.

\section{SECURITY PUBLIC IN BRAZIL: ONLENDING AND PUBLIC INVESTMENTS AND HOMICIDE FEES}

\begin{abstract}
Security has become one of the major themes of public and social agenda, including Brazil. Generally, security policies occur in interface with urban policies, so, it's worth warning: the government projects related to security, if not a proposal for inclusion of all, they will fail. Regarding to geography, the subject gains impact inside the field of what is known by Geography of Violence or Crime, in which studies specialized the empirical basis and promote guided reflections on social. Treated especially in the Federal Constitution, public safety still slides in the materialization of the projects. The transfers to the states often happen for political maneuvers and not based on indicators or needs. Therefore, we see states like Alagoas and Sergipe, with insignificant transfers and a high homicide rate. On the other hand, the largest receivers of funds, Sao Paulo and Rio de Janeiro, are those with the largest reduction in homicides.
\end{abstract}

Keywords: Security public. Geography of Violence. Brazil.

\section{INTRODUÇÃO}

A segurança se converteu em um dos principais temas da agenda pública social em escala mundial, independente da condição econômica do país. No Brasil, inclusive, existe a Secretaria Nacional de Segurança Pública, subordinada ao Ministério da Justiça. Geralmente, as políticas de segurança ocorrem em interface com as políticas urbanas. Portanto, logo de partida, antes de qualquer

$\begin{array}{llllll}\text { Caminhos de Geografia } & \text { Uberlândia - MG } & \text { v. 19, n. } 67 & \text { Set/2018 } & \text { p. 219-233 } & \text { Página } 219\end{array}$


discussão teórica, vale alertar: os projetos governamentais relacionados à segurança, caso não sejam dentro de uma proposta de inclusão de todos os segmentos da sociedade brasileira, estarão fadadas ao fracasso iminente.

Na Ciência Geográfica, o assunto se associa, diretamente, com a chamada Geografia da Violência e a Geografia do Crime. Estas áreas da Geografia têm evoluído, significativamente, nos últimos anos, ampliando as possibilidades de estudos (como no espaço urbano, os conflitos no campo, nos estudos políticos, relacionados ao meio ambiente, etc.), e, ao mesmo tempo, aprofundando os temas, como nos conceitos de violência, insegurança, sociabilidade, além da própria segurança.

No contexto brasileiro, a Constituição Federal de 1988, no Título V (Da defesa do Estado e das Instituições Democráticas), Capítulo III, trata exclusivamente da Segurança Pública: de acordo com o Art. 144, a "segurança pública, dever do Estado, direito e responsabilidade de todos, é exercida para a preservação da ordem pública e da incolumidade das pessoas e do patrimônio" (BRASIL, 1998, p. 79). Portanto, segurança pública corresponde à segurança do público, da coletividade e dos cidadãos, seja em espaços públicos, como as ruas, praças e estabelecimentos públicos, seja nos espaços privados de residência, trabalho e lazer. Para Souza (2008, p. 150), "idealmente, a segurança pública é um conjunto de ações, medidas e intervenções, em diferentes domínios (...) que deve ir construindo as condições para uma segurança maior e para a redução dos riscos".

Assim, a segurança se torna um "paradigma do governo", por meio do qual se criminalizam determinados grupos da sociedade e o medo do crime e da desordem são utilizados como pretexto para controle social, além de fomentar a "indústria da segurança" e a "indústria da mídia" (SOUZA, 2008). Isso porque, de fato, o Estado atual, impulsionado pela lógica capitalista de privatização dos serviços públicos, não protege a sociedade e, pior, prejudica a liberdade.

Nesse sentido, de acordo com Bauman (2003, p. 10), ambos são "valores igualmente preciosos e desejados que podem fazer bem ou mal equilibrados, mas nunca inteiramente ajustados e sem atrito". O ajuste é o objetivo das políticas e ainda não concretizado. Certamente, a segurança é uma necessidade, todavia não se pode tê-la em troca da liberdade. A liberdade "conquistada" é aqui entendida como a capacidade de fazer as coisas da maneira que se quer, sem que ninguém interfira ou obrigue a fazer (BAUMAN, 2003).

A segurança nem sempre apresentou um caráter coletivo e/ou público. Durante boa parte da história, nas sociedades ocidentais, as questões relacionadas à segurança eram de cunho privado, sem cobranças diretas as autoridades governamentais e, por conseguinte, ao Estado. Foi apenas no mundo moderno que a garantia da ordem interna se transformou em um problema público e de caráter coletivo (SAPORI, 2007).

O objetivo principal deste artigo é discorrer acerca da segurança pública no Brasil, sobretudo refletido sobre a relação entre repasses públicos e taxas de homicídios e sobre as políticas públicas de segurança. Para contemplar esse objetivo, caminha-se pelos objetivos específicos, como apresentar a história da segurança, abordar e compreender o Sistema Judicial Brasileiro, com ênfase no sistema carcerário, e, finalmente, debater as políticas públicas voltadas para a segurança.

Os procedimentos metodológicos foram: levantamento de referenciais teóricos acerca do tema, especialmente na correlação com outras ciências; levantamento de dados estatísticos sobre a realidade brasileira quanto à segurança pública; elaboração de produções cartográficas, como gráficos e tabelas, com a finalidade de ilustrar os dados levantados; e, por fim, sistematização das informações nesta redação final.

\section{O CONTEXTO HISTÓRICO DA SEGURANÇA}

$\mathrm{Na}$ Europa, entre os séculos IX e XIV, as comunidades rurais de camponeses desenvolveram sistemas de caridade de cunho voluntário, desde esmolas e alimentos aos pobres até a fundação de abrigos e hospitais aos desafortunados (SAPORI, 2007). Assim, surgem as poorhouses, que eram casas/asilos que proporcionavam uma série de serviços aos pobres, inclusive de segurança, administradas pela municipalidade e de cunho regional (SAPORI, 2007). Entretanto, o contexto social de incerteza, como epidemias, guerras e crises econômicas, deixavam o sistema vulnerável (SAPORI, 2007). No século XVII, duzentos anos após as poorhouses, com o incremento de financiamento das autoridades centrais dos estados europeus, surgem as workhouses, que eram espaços destinados ao confinamento e à reinserção social por meio de trabalho (SAPORI, 2007). Em resumo, ela consiste na gênese das prisões.

\begin{tabular}{llllll}
\hline Caminhos de Geografia & Uberlândia - MG & v. 19, n. 67 & Set/2018 & p. 219-233 & Página 220
\end{tabular}


Partindo disso, criou-se uma consciência coletiva de que a violência e a criminalidade eram problemas menos de ordem social e mais de responsabilidade dos Estados. Concretamente, isso ocorre com a institucionalização do sistema prisional, de organizações policiais profissionalizadas e de um sistema judicial formalizado. Antes disso, porém, a segurança era restrita a cada comunidade e garantida por agentes específicos.

No Império Romano, existia um grau de centralização das atribuições da manutenção da ordem coletiva: surge a administração policial pública para a manutenção da ordem nas ruas. Assim, o prefeito da cidade era encarregado de comandar os patrulheiros de rua, que por sua vez, comandavam os stationarii, que ficavam em postos fixos (SAPORI, 2007). Além disso, emergiu a primeira manifestação de direito formalizado, codificado e administrado por representantes da autoridade central: "[...] o direito das pessoas, da família, da hereditariedade, da propriedade, além do direito criminal [...]” (SAPORI, 2007, p. 22).

Com a queda do Império Romano, os órgãos especializados de polícia desapareceram e o direito romano sucumbiu. O período medieval proporcionou uma descentralização acentuada nas funções de polícia e de justiça, sendo que a segurança passou, naquele momento, para atributo individual (SAPORI, 2007).

\begin{abstract}
"Deve-se ter em mente que a violência era crônica nas comunidades rurais e urbanas que compunham os feudos. A inserção da violência casual, aleatória, imprevisível era intensa. A atuação de bandos de guerreiros nômades, ladrões e piratas era constante, definindo um cenário social de alto grau de insegurança" (SAPORI, 2007, p. 23).
\end{abstract}

Os senhores feudais dispunham de funcionários armados que os protegiam. A coletividade não possuía proteção. Por isso, surgem grupos voluntários de vigilância e repressão do banditismo local: os Tything, na Inglaterra (século X e XIII), os Maréchausseé, na França (século XIV) e a Santa Hermandad, na Espanha (SAPORI, 2007). O caráter de justiça pertencia ao senhor local, em nome do rei. Em suma, os problemas eram resolvidos dentro de cada clã, por meio de "justiça com as próprias mãos" e/ou "direito à vingança", em uma verdadeira violência constante como padrão de sociabilidade (SAPORI, 2007).

Com a ascensão do Estado Absolutista, durante o século XVI, e do Estado-nação, no final do século XVIII, o tema passou a ter outra conotação: pautada na soberania por parte do Estado que promulgava leis e designava autoridades da nobreza para aplicá-las na população (SAPORI, 2007). Ou seja, naquele momento boa parte da população já estava exclusa da reciprocidade de direitos e obrigações e, uma classe mais abastada gozava de privilégios, como a impunidade (SAPORI, 2007). Os resultados são uma disseminação de unidades carcerárias na Europa ocidental e a constituição de forças policiais em praticamente todos os países.

Há, assim, "uma mudança do privado para o público, da organização descentralizada para a organização centralizada, da autoridade feudal para a autoridade estatal” (SAPORI, 2007, p. 28). No Estado-nação, o processo histórico monopoliza a violência física no âmbito do poder central, criando um campo vasto e aberto para a propagação de aparatos policias, até porque, já havia furtos e roubos pelas ruas das cidades.

"As polícias municipais até então existentes nas diversas sociedades européias vão sendo paulatinamente reguladas e limitadas em suas atribuições ou mesmo incorporadas pelas polícias nacionais. As polícias militares são, desse ponto de vista, a expressão institucional mais visível do Estado-nação" (SAPORI, 2007, p. 31).

As organizações policiais se consolidaram no século XIX nas sociedades ocidentais, em paralelo aos sistemas prisionais e judiciais. Na contemporaneidade, existem dois subsistemas de polícias, segundo Sapori (2007): monistas e pluralistas. O primeiro ocorre quando há apenas uma única organização policial de abrangência nacional e subordinada à autoridade central, como ocorre na Noruega, Japão e Israel (SAPORI, 2007). Já a pluralista acontece quando existem dois ou mais subsistemas de policiais, com os casos da Austrália (sete polícias), Alemanha (polícias regionais e três nacionais), Inglaterra (quarenta polícias provinciana e a Polícia Metropolitana de Londres), Estados Unidos (entre 17 e 25 mil polícias), Itália, México, Índia, Canadá, etc., além do próprio Brasil (SAPORI, 2007), como é abordado adiante com mais detalhes.

A porção seguinte desta redação dedica-se à realidade brasileira, transitando pelo sistema brasileiro de segurança pública. Essa sistematização é fundamental para compreender o cenário brasileiro e, por conseguinte, as políticas públicas de segurança.

$\begin{array}{llllll}\text { Caminhos de Geografia } & \text { Uberlândia - MG } & \text { v. 19, n. } 67 & \text { Set/2018 } & \text { p. 219-233 } & \text { Página } 221\end{array}$




\section{A SEGURANÇA PÚBLICA E O SISTEMA JUDICIAL BRASILEIRO}

No Brasil, a Constituição Federal de 1988 regulamenta os órgãos responsáveis pela segurança pública: i) polícia federal; ii) polícia rodoviária federal; iii) polícia ferroviária federal; iv) polícias civis; e, v) polícias militares e corpos de bombeiros militares (BRASIL, 1998). Já quanto às guardas municipais, a Constituição prevê no que os municípios poderão constitui-las destinadas à proteção de seus bens, serviços e instalações, conforme dispuser a lei municipal (BRASIL, 1998).

A polícia federal destina-se a apuração das infrações penais contra a ordem política e social ou em detrimento de bens, serviços e interesses da União ou de suas entidades autárquicas e empresas públicas, prevenir ou reprimir o tráfico ilícito de entorpecentes e drogas afins, o contrabando e o descaminho, exercer as funções de polícia marítima, aérea e de fronteira e exercer, com exclusividade, as funções de polícia judiciária da União (BRASIL, 1998). A polícia rodoviária federal destina-se ao patrulhamento ostensivo das rodovias federais, enquanto que a polícia ferroviária federal ao patrulhamento das ferrovias federais (BRASIL, 1998).

Certamente, os serviços que estão mais próximos da sociedade são os de polícias civil e militar. As polícias civis, conduzidas por delegados de polícia, são responsáveis, ressalvada a competência da União, pelas funções de polícia judiciária e pela apuração de infrações penais, exceto militares. Já às polícias militares cabe o policiamento ostensivo e a preservação da ordem pública, sendo que aos corpos de bombeiros militares, incumbem à execução de atividades de defesa civil. Ambas as polícias, somadas às forças auxiliares e reserva do Exército, subordinam-se aos Governadores dos Estados, do Distrito Federal e dos Territórios.

"No Brasil, revela-se um quadro em que tanto o Estado social como o Estado legal são fracos, pois incapazes de universalizar, de fato, os direitos sociais e os direitos civis. A garantia desses direitos permanece restrita a uma minoria, de modo que a amplas parcelas da população resta um Estado precário e repressor" [grifo do autor] (NEME, 2005, p. 134).

O Estado social, grifado na citação anterior, vem vivendo uma fase de transformação das suas características, no que se relaciona ao tratamento à sociedade, principalmente aos excluídos e margeados. Em outros termos, ele passou de um Estado que pensa nas questões sociais para um "Estado excludente, da justiça criminal, penal ou do controle do crime" (BAUMAN, 2007, p. 55).

Logo, é necessário que se pense em uma efetiva articulação entre a prevenção e a segurança para que as políticas nacionais, regionais e locais não resultem em mais segregação, aumento da violência e ampliação do sentimento/da sensação de insegurança em todos os espaços e na população em sua totalidade.

Além disso, segundo Benevides (1983, p. 51), "enquanto não descobre, a polícia fabrica suspeitos; impunemente fornece aos jornais os nomes de acusados: porteiros de prédios, bombeiros hidráulicos, pedreiros, empregadas domésticas". Certamente, o modelo policial brasileiro é problemático e precisa de profundo debate, inclusive quanto à desmilitarização e à propagação da polícia comunitária, como propõe Fernandes (2017).

Os subsistemas judiciais também são importantes e fazem parte da segurança pública. Neles ocorrem duas situações: a) as normas que regem a determinação das condutas criminosas (código penal e leis) e o funcionamento do sistema por meio do procedimento penal; e, b) as organizações encarregadas de sua aplicação (tribunais e defensorias, como exemplo). Assim, existem dois tipos de sistemas judiciais: os modelos acusatórios, como nos Estados Unidos, na Nova Zelândia e na Inglaterra, e os modelos inquisitoriais, como exemplo, França, Brasil, Itália, Argentina e Alemanha (SAPORI, 2007).

O sistema judicial brasileiro, inspirado no francês, é composto, além das polícias já mencionadas, pelo Ministério Público (MP), a Defensoria Pública e o Judiciário. O MP é uma organização de níveis estadual e federal vinculado institucionalmente ao Executivo (mas, não faz parte dele, pois tem autonomia financeira e administrativa) e tem como missão representar o Estado nas ações penais. A Defensoria Pública tem como objetivo representar os interesses do acusado que não tem condição econômica de adquirir uma defesa particular. Por fim, o Judiciário, representado pelos juízes e desembargadores, zela pelo cumprimento dos rituais legais do processo criminal.

Os procedimentos da justiça brasileira se iniciam com o registro do suposto fato criminoso pela Polícia Militar. Ela, que não tem atribuições investigativas, comunica o registro à Polícia Civil, que, por sua vez, busca indícios e evidências da materialidade do caso. A investigação resulta no inquérito

$\begin{array}{llllll}\text { Caminhos de Geografia } & \text { Uberlândia - MG } & \text { v. 19, n. } 67 & \text { Set/2018 } & \text { p. 219-233 Página } 222\end{array}$


policial. Ele é encaminhado ao MP que vai avaliar o fundamento do caso. Havendo a materialidade do crime, os promotores formalizam a denúncia do suposto autor, que passa, então, a ser reconhecido como réu. Após esta fase de reconhecimento e o acatamento da denúncia pelo juiz, inicia-se o fluxo processual, chamado de instrução criminal. O Judiciário passa a ter papel fundamental e as ações ocorrem no fórum. O MP e a Defensoria Pública atuam com considerações escritas e verbais. O julgamento, que raramente envolve júri no Brasil, é encerrado quando é sentenciada a culpabilidade do réu. Então, o Executivo, por meio das organizações prisionais, atua no encarceramento.

Os procedimentos básicos anteriores são os que ocorrem na maioria dos casos. Entretanto, alguns crimes têm procedimentos distintos. Um exemplo é o homicídio doloso, que é o único caso que está previsto a participação do júri popular. O homicídio doloso ocorre quando a pessoa age com intenção ou assume a intenção de matar outra pessoa (BRASIL, 1984). Ele corresponde ao maior grau de crime da esfera brasileira, ocorrendo, apenas, de pessoa física para pessoa física (BRASIL, 1984).

Existem casos em que não há o inquérito policial, como quando ocorrem eventos de gravidade leve e causas que não ultrapassem quarenta salários mínimos, passando, então, a um ritual processual chamado de sumaríssimo (BRASIL, 1995). Os casos são resolvidos, por meio dos Juizados Especiais Civis e Criminais (antigo Juizado de Pequenas Causas), em audiências em que a defesa e acusação se manifestam e o juiz define a sentença (BRASIL, 1995).

A teoria não reflete a prática exercida na realidade brasileira. Além de o sistema judicial ser deficitário em infraestrutura e profissionais, ele é passível de muitas injustiças e preconceitos. Isso ocorre pela dificuldade do sistema agir, com investigação e julgamento com coerência e honestidade na "punição" dos infratores, onde a maioria dos casos é encerrada sem solução, e pelo alto índice de privilégios a determinados grupos sociais, que escapam de punições por influência direta dos detentores do poder.

\section{O SISTEMA CARCERÁRIO BRASILEIRO}

Além do aparato policial e do subsistema judicial, vale a pena abordar as chamadas "instituições de controle social" (GOES, 2004, p. 219) ou "estabelecimentos penais: todos aqueles utilizados pela justiça com a finalidade de alojar pessoas presas, quer provisórios quer condenados, ou ainda aqueles que estejam submetidos à medida de segurança" (BRASIL, 2011).

De acordo com Brasil (2011), são modelos desses espaços: i) as cadeias públicas, destinadas ao recolhimento de pessoas presas em caráter provisório; ii) penitenciárias, destinadas ao recolhimento de pessoas presas com condenação à pena privativa de liberdade em regime fechado (são divididas em Penitenciárias de Segurança Máxima Especial - celas individuais - e as Penitenciárias de Segurança Média ou Máxima - celas individuais e coletivas); iii) colônias agrícolas, industriais ou similares, destinados a abrigar pessoas presas que cumprem pena em regime semiaberto; iv) casas do albergado, destinadas a abrigar pessoas presas que cumprem pena privada de liberdade em regime aberto ou pena de limitação de fins de semana; v) centros de observação criminológicas; vi) estabelecimentos para idosos; e, por fim, vii) hospitais de custódia e tratamento psiquiátrico.

Esses espaços são gerenciados pela Federação ou pelas Unidades da Federação. As unidades federais, criadas pela Lei 7.210 de 1984, de acordo com Brasil (2011), servem para abrigar "criminosos de alta periculosidade (...). O objetivo do governo é, ao mesmo tempo, garantir um isolamento dos chefes dos crimes organizados e aliviar a tensão no sistema carcerário estadual".

Ainda com base no Ministério da Justiça, foram planejadas cinco unidades com capacidade para 208 pessoas: a primeira inaugurada em junho de 2006 foi a de Catanduvas (PR); a segunda, em dezembro de 2006, a unidade de Campo Grande (MS); as unidades de Porto Velho (RO) e Mossoró (RN) estão concluídas; e, por fim, a unidade de Brasília (DF) está prevista para ser inaugurada em 2015, mas que em 2017 ainda não foi concluída. Já aos estabelecimentos prisionais estaduais cambem diretamente às administrações de cada Unidade da Federação.

No Brasil, os dados nacionais e estaduais acerca da população carcerária e da capacidade do sistema são detalhados pelo Ministério da Justiça. A Figura 1 apresenta a população carcerária brasileira, entre 2000 e 2015, tomando dezembro como o mês base.

No período selecionado, a população carcerária brasileira triplicou, passando de 233 mil para quase 700 mil. Na série, foram dois momentos de grande crescimento: o primeiro, de 2000 até 2006, com aumento de $32,5 \%$ entre 2000 e 2003 e de $30,1 \%$ entre 2003 e 2006; e, o segundo, na atualidade,

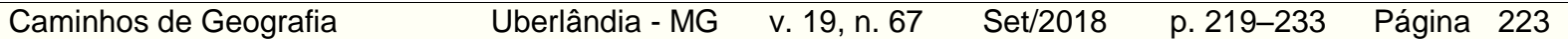


entre 2012 e 2015, quando o crescimento foi de $27,1 \%$. Em todos os anos o crescimento foi superior a $2 \%$, menos entre 2000 e 2001, em que o crescimento foi de $0,48 \%$. Em contrapartida, segundo os dados do Governo Federal, o Brasil tem um déficit de 327.417 vagas, ou seja, apresenta uma taxa de ocupação prisional de $188,2 \%$ e uma taxa de aprisionamento de 341,7 para cada cem mil pessoas.

Figura 1: Brasil: População carcerária, 2000-2015

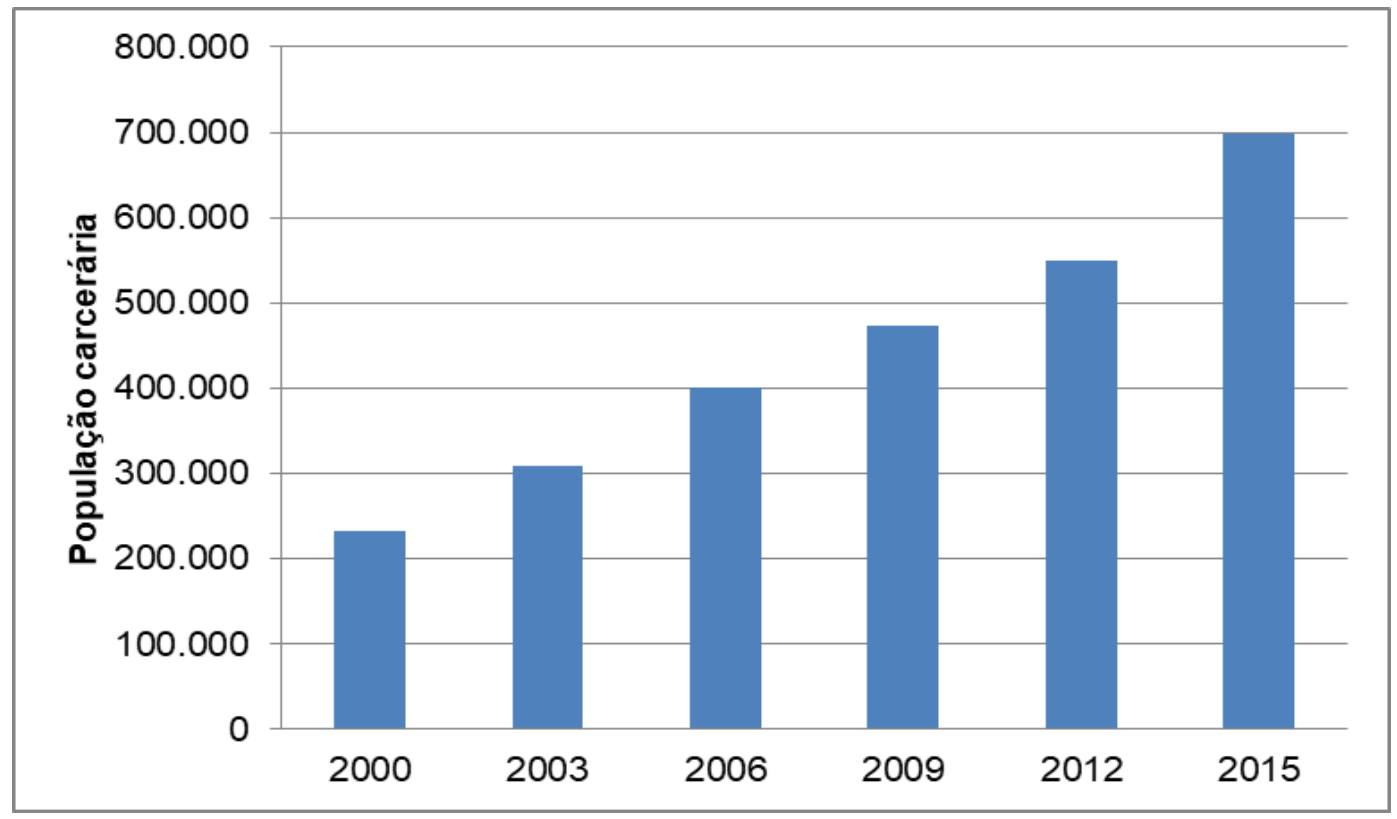

Fonte: Brasil (2017).

As possibilidades de explicação para esse aumento da população carcerária no Brasil são múltiplas. Neste artigo, apresentam-se duas possibilidades. Uma primeira explicação está na alta quantidade de presos provisórios, isto é, pessoas que não foram condenadas, em nenhuma instância de poder, e que aguardam julgamento. Em 2015, 37\% dos privados de liberdade estavam nessa condição. No Estado do Ceará, 67\% dos presos em dezembro de 2015 encontravam-se custodiados no sistema prisional há mais de noventa dias sem condenação. Já entre os presos provisórios de Sergipe, $97 \%$ estão aprisionados há mais de noventa dias sem condenação. Nesse ponto, é fundamental ressaltar que a criação das audiências de custódias tem diminuído a proporção de presos nessa condição. Uma segunda explicação está na motivação para a prisão: segundo o Levantamento Nacional de Informações Penitenciárias, $28 \%$ dos brasileiros presos estão em razão da lei de drogas, $25 \%$ por roubo e $13 \%$ por furtos. Portanto, segundo o levantamento, o hiperencarceramento se deve aos crimes não violentos (BRASIL, 2014).

A melhor maneira de comparar a população carcerária brasileira, por Unidade da Federação, é a "população carcerária por cem mil habitantes". Por isso, a Tabela 1 apresenta o ranking das Unidades da Federação por população carcerária em cem mil habitantes, em dezembro de 2015, sendo que o índice médio brasileiro era, em 2015, de 341,7 presos por grupo de cem mil habitantes.

Entre as Unidades da Federação, nove apresentavam dados maiores que a média nacional. Entretanto, a diferença entre o Mato Grosso do Sul, líder, e a Bahia, última classificada, é consideravelmente alta (quase seis vezes maior). Entre 2010 e 2015, os três primeiros colocados não se alteraram, havendo apenas uma reorganização do posicionamento - em 2010, o Acre liderava, Rondônia aparecia em segundo lugar e o Mato Grosso do Sul era o terceiro. Outra constatação é que todas as Unidades da Federação apresentaram taxas superiores a 100,0 presos por cem mil habitantes - em 2010, Alagoas, Maranhão e Piauí, as três últimas, respectivamente, possuíam taxas de $98,0,86,7$ e 86,3 presos por cem mil habitantes.

$\begin{array}{llllll}\text { Caminhos de Geografia } & \text { Uberlândia - MG } & \text { v. 19, n. } 67 & \text { Set/2018 } & \text { p. 219-233 Página } 224\end{array}$


Tabela 1: Unidades da Federação: População carcerária por 100.000 habitantes, 2015.

\begin{tabular}{clcclc} 
Posição & Unidade da Federação & Índice & Posição & Unidade da Federação & Índice \\
\hline $\mathbf{0 1}$ & Mato Grosso do Sul & 595,5 & $\mathbf{1 4}$ & Mato Grosso & 273,9 \\
$\mathbf{0 2}$ & Rondônia & 583,3 & $\mathbf{1 5}$ & Rio Grande do Sul & 273,7 \\
$\mathbf{0 3}$ & Acre & 578,6 & $\mathbf{1 6}$ & Santa Catarina & 270,9 \\
$\mathbf{0 4}$ & São Paulo & 525,0 & $\mathbf{1 7}$ & Amazonas & 269,3 \\
$\mathbf{0 5}$ & Distrito Federal & 494,9 & $\mathbf{1 8}$ & Paraíba & 265,1 \\
$\mathbf{0 6}$ & Espírito Santo & 476,2 & $\mathbf{1 9}$ & Sergipe & 231,6 \\
$\mathbf{0 7}$ & Paraná & 471,3 & $\mathbf{2 0}$ & Rio Grande do Norte & 225,4 \\
$\mathbf{0 8}$ & Roraima & 441,4 & $\mathbf{2 1}$ & Goiás & 218,3 \\
$\mathbf{0 9}$ & Ceará & 387,3 & $\mathbf{2 2}$ & Tocantins & 216,7 \\
$\mathbf{- -}$ & Média brasileira & 341,7 & $\mathbf{2 3}$ & Alagoas & 200,7 \\
$\mathbf{1 0}$ & Pernambuco & 339,9 & $\mathbf{2 4}$ & Pará & 157,1 \\
$\mathbf{1 1}$ & Amapá & 337,3 & $\mathbf{2 5}$ & Piauí & 116,1 \\
$\mathbf{1 2}$ & Rio de Janeiro & 335,7 & $\mathbf{2 6}$ & Maranhão & 114,3 \\
$\mathbf{1 3}$ & Minas Gerais & 314,8 & $\mathbf{2 7}$ & Bahia & 100,1 \\
\hline
\end{tabular}

Fonte: Brasil (2017).

A partir do momento que a pessoa é recolhida para um desses estabelecimentos prisionais, o modo de vida dela, de seus amigos e familiares se altera significativamente. Para Goes (2004, p. 220), "as relações entre 0 interior e 0 exterior das muralhas das penitenciárias tem merecido atenção específica" por diversos motivos, entre os quais se destacam dois: i) a inconstante relação entre os moradores da cidade e os "estranhos" que vem de fora, como parentes e amigos dos presidiários, e, ii) o modo de vida dentro das penitenciárias, associado a repressão, violência, rebelião, venda e consumo de drogas, etc.

Goes (2009, p. 21), se propôs a estudar a reação da população prisioneira ao controle das instituições e, "em especial, as rebeliões carcerárias que representam os momentos mais agudos desta reação". No livro $A$ recusa das grades ela transita pelo contexto nacional do projeto geral de implantação de um controle social e disciplinar que compatibiliza o comportamento das pessoas de acordo com os interesses do capitalismo internacional para entender a complexidade das relações da população carcerária. É preciso aprofundar esse tema. A partir do exposto, as políticas públicas tornam-se indispensáveis para a pauta da segurança pública brasileira.

\section{AS POLÍTICAS PÚBLICAS DE SEGURANÇA}

No Brasil, a segurança pública sempre se deparou com um "peso histórico autoritário sobre as instituições estatais encarregadas de realizar o controle social" (NEME, 2005, p. 129). Assim, as questões relativas ao controle social não foram tratadas democraticamente na histórica da política pública de segurança. Além disso, a relativa demora em se solucionar o problema da segurança pública brasileira reflete na situação caótica contemporânea na qual ela se encontra.

Até a última década do século $X X$, as políticas públicas de segurança eram incipientes no Brasil. Apenas no final da década de 1990 que surgiram as primeiras iniciativas de mudanças mais amplas, entre as quais se destacaram a criação da Secretaria Nacional de Segurança Pública e da Secretaria Especial dos Direitos Humanos, o lançamento do Programa Nacional de Direitos Humanos (1996) e do Plano Nacional de Segurança Pública (2001), e, por fim, o estabelecimento do Sistema Único de Segurança Pública.

"Essas políticas significaram uma nova abordagem da questão da segurança, uma vez que pela primeira vez o governo federal assumiu a elaboração de um plano nacional de segurança pública, tentando articular estados e municípios com objetivo de tratar com seriedade dos problemas de insegurança" (NEME, 2005, p. 130).

Ainda que possam ter proporcionado um relativo avanço, sobretudo em comparação com a situação que existia, elas foram insuficientes, principalmente por não abordarem as questões regionais e culturais que influenciam nas relações pessoais e na violência e insegurança. As políticas de segurança se limitam às ações, de intervencionismo governamental, voltadas às soluções paliativas, que visam respostas à imprensa e à opinião pública, especialmente com situações de comoção nacional. Essas soluções são esporádicas, espaçadas e desconectadas do contexto real, e, portanto, praticamente sem efeitos concretos e resultados satisfatórios.

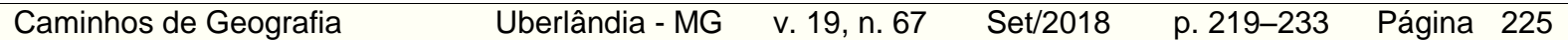


Além disso, antes mesmo das próprias políticas públicas relacionadas à segurança, vive-se uma fase de grande defasagem na estrutura física e nos serviços públicos que deveriam garantir a segurança e na estrutura imaterial, com alguns profissionais não capacitados - inclusive emocionalmente - para atender as necessidades da população. Portanto, além de melhorar as estruturas físicas e os serviços, as políticas de segurança devem direcionar-se a uma associação eficiente entre policial e direitos humanos e não a ações com brutalidade, tratamento diferenciado - juízo de valor - e coerção/repressão (FERNANDES, 2017).

No Brasil, a segurança passa pela classe dominante e pelos detentores do poder político. Essas classes quase sempre exigem e aprovam leis mais duras e com maior repressão contra os "bandidos", além de criarem estereótipos dos criminosos e considerá-los irrecuperáveis para o convívio social.

"Dois aspectos são salientados: a morte como exemplo e a morte como solução mais eficiente. Em ambos os casos, está presente a concepção que permeia uma especial relação da polícia com o bandido: a concepção de limpeza. Trata-se de limpar a sociedade, expurgando-a de seus maus elementos, quando vistos como irrecuperáveis" (BENEVIDES, 1983, p. 51).

O combate à violência não pode ser por meio de mais violência. A busca pela ordem não pode ser justificada a qualquer custo, muito menos nas seguintes dicotomias abordadas por Benevides (1983, p. 83): "culpado/inocente, irrecuperável/recuperável, perverso/'boa gente', como também na própria noção de 'justiça'". Em síntese, formas de punição física, a saber, tortura e maus-tratos, como forma de "pagar pelo que fez" e "aprender o que é bom". Assim, trata-se de um castigo, onde, para a autora, o policial deixa de ser um funcionário, um burocrata eficiente, um "homem da ordem", para transformar-se num justiceiro.

Essa forma de justiça só corrói a estrutura dos órgãos de segurança pública. Não é, certamente, nenhuma justiça com as próprias mãos de policiais ou de membros da sociedade, tampouco grupos de extermínios, que se vai avançar no embate contra a violência e a insegurança urbana brasileira. Assim como se deve abdicar da incorporação de torturas e métodos similares.

Uma política pública repressiva é a "tolerância zero", originária de Nova lorque, nos Estados Unidos da América, e adotada por diversos governos federais, estaduais, provinciais e até municipais, por todo o mundo. Para Pedrazzini (2006, p. 89), nessa política "não se combate tanto o crime, mas sim a pobreza, como meio social e cultura popular, e o bairro dito 'marginal' considerando como o meio 'natural' para sua propagação". Já para Sapori (2007, p. 77), ela é "incapaz de responder às desordens suscitadas pela desregulamentação da economia e pela pauperização relativa e absoluta de amplos segmentos do proletariado urbano".

Já um exemplo brasileiro vem de políticas desenvolvidas no estado de São Paulo. Segundo Goes (2004, p. 221-221), o governo de Franco Montoro (1983-1987) procurou criar a Política de Humanização dos Presídios durante o contexto de transição da "repressão para a democracia". Entretanto, para a autora, as propostas dessa política indicam que "nunca se chegou a questionar as funções de violência e punição, próprias do sistema penitenciário". No caso, ela apenas procurou-se utilizá-las por meio de métodos menos violentos. Logo, com a proximidade das eleições, as políticas mais duras quanto à segurança, chamados de "pacote de segurança" - lançados por Orestes Quércia, vice-governador de Montoro e candidato à sucessão - ganharam força dentro do Partido do Movimento Democrático Brasileiro (PMDB). A eleição de Quércia (1983-1986) foi uma vitória para os setores mais reacionários e um início de consequências graves aos que viviam nas prisões. As consequências negativas vivenciadas nas penitenciárias paulistas vieram, como resposta, por meio das rebeliões (GOES, 2009).

Assim, a "recusa das grades" (GOES, 2009, p. 87) é uma forma coletiva (totalidade ou grupos) de protestar contra as péssimas condições de vida nos presídios e as punições sem julgamento e legislação pertinente. Grande parte das rebeliões ocorre nessa perspectiva. Entretanto, existem também, aqueles casos relacionados às tentativas de fugas.

Diante de todo o exposto e como forma de repudiar e muitas vezes de segurança, as pessoas, no momento de incerteza, passam a "negar a violência". Essa negação é, segundo Gaviria (2008, p. 78), a "forma de manifestar uma relação de alteridade com o fenômeno". Em certas localidades, as pessoas agem como se nada estivesse acontecendo, negando, efetivamente, que o espaço é violento e/ou inseguro e/ou "fingindo que não vê".

$\begin{array}{llllll}\text { Caminhos de Geografia } & \text { Uberlândia - MG } & \text { v. 19, n. } 67 & \text { Set/2018 } & \text { p. 219-233 } & \text { Página } 226\end{array}$


Assim, atrelado a todo esse processo, e com certeza uma das mais perversas consequências nas relações sociais, ocorre à chamada "lei do silêncio". Entre outros fatores, ela é produzida pelo medo e pela desconfiança e cria na pessoa a sensação de que dependendo do que ela disser a determinadas pessoas, algo ruim pode acontecer a ela ou a sua família.

Todavia, o fato é que não ocorre apenas quando as pessoas se fecham para o que vem de fora, mas também gera uma incomunicabilidade entre pessoas, inclusive da própria esfera de convivência. Fernandes (2017) abordou a transformação da sociabilidade a partir do aumento da violência e da insegurança objetiva, logo, em relação à segurança. Portanto, passam a viver suas vidas normais, entretanto, impedidas de se apropriarem do espaço coletivamente ou se sentirem pertencentes concretamente a eles (SILVA, 2004). Quando, apesar de sofrer algum ato violento ou ameaça, se curva ao medo e passa a conviver com aquilo sem qualquer denúncia ou atitude.

Em luta contra o exposto, algumas localidades optam para o discutido toque de recolher ou toque de proteger. Ele consiste, basicamente, na proibição de determinados grupos ou faixas etárias de frequentar vias públicas, logradouros e estabelecimentos públicos em determinadas horas (ENDLICH; FERNANDES, 2014). Dentro dessa óptica, os autores dialogam associando o tema à vida urbana que pressupõe encontros.

Os próximos dados abordam os recursos recebidos pelas Unidades da Federação brasileira e os investimentos públicos estaduais com segurança, por habitante, ou seja, o capital para a promoção da segurança pública, e, depois, os indicadores de homicídios, para possíveis reflexões acerca da aplicabilidade e materialização das políticas. Evidentemente, espera-se que esses dados gerem inquietações para futuros trabalhos no âmbito da Geografia da Violência e do Crime. Assim, inicia-se com a Tabela 2, que apresenta a quantidade total de recursos repassados pelo Fundo Nacional de Segurança Pública, por meio dos convênios, às Unidades da Federação, entre o período de 2010 e 2014. É fundamental explicar o procedimento quanto ao levantamento realizado: os dados foram encontrados no Portal da Transparência do Governo Federal (BRASIL, 2018) e referem-se aos convênios vinculados ao órgão 30911 - Fundo Nacional de Segurança Pública - no período de janeiro de 2010 a dezembro de 2014, sendo considerado o ano do chamado "número original", que funciona como um protocolo do convênio. Na realização da pesquisa inexistiam dados disponibilizados para os anos posteriores a 2014.

O Estado de Pernambuco foi o maior receptor de repasse do Fundo Nacional de Segurança Pública, somando os valores entre 2010 e 2014, com $R \$ 60.392 .835,17$. Isso pode ajudar a explicar o fato do estado deixar de ter a maior taxa de homicídio do Brasil. O valor recebido pelos pernambucanos é, aproximadamente, igual à soma dos valores de Roraima, Alagoas, Espírito Santo, Sergipe, Paraíba, Rio Grande do Norte e Piauí. Apesar disso, Pernambuco é apenas a décima Unidade da Federação em investimento por habitantes, com $\mathrm{R} \$ 6,87$. Os Estados do Paraná, Rio Grande do Sul, São Paulo e Rio de Janeiro completam as cinco primeiras posições, que somam $36 \%$ dos R $\$ 724$ milhões repassados pelo Fundo às Unidades da Federação entre 2010 e 2014. Em contrapartida, quatro Estados receberam menos de dez milhões de reais no período: Sergipe (R $\$ 9,27 \mathrm{mi})$, Espírito Santo $(\mathrm{R} \$ 8,81 \mathrm{mi})$, Alagoas $(\mathrm{R} \$ 8,42 \mathrm{mi})$ e Roraima $(\mathrm{R} \$ 3,39 \mathrm{mi})$. Isso pode ajudar a explicar o fato de Sergipe e Alagoas possuírem as maiores taxas de homicídios no Brasil. Quanto ao valor investido por habitantes no período de 2010 a 2014, o Acre apareceu no topo do ranking com $\mathrm{R} \$ 38,84$ por habitante. Esse valor é o dobro do Amapá, segundo colocado, com $\mathrm{R} \$ 18,85$ por habitante, e quase 35 vezes maior que o investido por São Paulo, último colocado no ranking, com $R \$ 1,12$ por habitante. No geral, 19 Unidades da Federação investiram menos que a média brasileira (R $\$ 8,31$ por habitante) e 11 delas gastaram menos da metade dessa média. O Paraná recebeu apenas $R \$ 5,72$ por habitante, considerando todo o período de 2010 a 2014, gerando uma média de $\mathrm{R} \$ 1,14$ por habitante/ano.

Analisando o período de 2010 a 2014, foi possível constatar que até 2012 o montante de repasse destinado às Unidades da Federação praticamente dobrou, atingindo $R \$ 257$ milhões em 2012, e depois despencou significativamente, ficando em apenas $R \$ 45$ milhões em 2014, ou seja, uma queda de $82 \%$ no repasse federal. Nesse sentido, em 2014, oito Unidades da Federação (30\%) não receberam nenhum repasse do Fundo Nacional de Segurança Pública. Na comparação entre 2013 e 2014, apenas quatro Unidades da Federação não apresentaram queda no repasse: Sergipe (aumento de 344\%), Bahia (aumento de 162\%), Maranhão (aumento de 93\%) e Distrito Federal (aumento de 27\%). Entre as que receberam recurso, as maiores quedas ocorreram no Paraná $(92 \%)$ e em Goiás (68\%). 
Tabela 2: Unidades da Federação: Recursos do Fundo Nacional de Segurança Pública, 2010 a 2014 , total e por habitantes

\begin{tabular}{rcrr} 
Posição & Unidade da Federação & Total no período (R\$) & R\$/Habitantes \\
\hline $\mathbf{0 1}$ & Acre & $28.492 .282,25$ & 38,84 \\
$\mathbf{0 2}$ & Amapá & $12.618 .808,68$ & 18,85 \\
$\mathbf{0 3}$ & Tocantins & $21.328 .617,58$ & 15,42 \\
$\mathbf{0 4}$ & Distrito Federal & $36.696 .713,85$ & 14,28 \\
$\mathbf{0 5}$ & Mato Grosso do Sul & $33.993 .029,86$ & 13,88 \\
$\mathbf{0 6}$ & Rondônia & $21.317 .093,71$ & 13,64 \\
$\mathbf{0 7}$ & Mato Grosso & $35.906 .611,67$ & 11,83 \\
$\mathbf{0 8}$ & Amazonas & $31.643 .044,78$ & 9,08 \\
$\mathbf{0 9}$ & Roraima & $3.399 .169,67$ & 7,55 \\
$\mathbf{1 0}$ & Pernambuco & $60.392 .835,17$ & 6,87 \\
$\mathbf{1 1}$ & Paraná & $59.730 .130,02$ & 5,72 \\
$\mathbf{1 2}$ & Santa Catarina & $32.595 .641,75$ & 5,22 \\
$\mathbf{1 3}$ & Rio Grande do Sul & $53.019 .475,52$ & 4,96 \\
$\mathbf{1 4}$ & Sergipe & $9.277 .336,04$ & 4,49 \\
$\mathbf{1 5}$ & Goiás & $25.844 .369,69$ & 4,30 \\
$\mathbf{1 6}$ & Pará & $31.558 .992,86$ & 4,16 \\
$\mathbf{1 7}$ & Piauí & $11.460 .682,53$ & 3,68 \\
$\mathbf{1 8}$ & Rio Grande do Norte & $11.358 .226,51$ & 3,59 \\
$\mathbf{1 9}$ & Alagoas & $8.420 .772,24$ & 2,70 \\
$\mathbf{2 0}$ & Paraíba & $10.080 .728,08$ & 2,68 \\
$\mathbf{2 1}$ & Rio de Janeiro & $41.118 .577,29$ & 2,57 \\
$\mathbf{2 2}$ & Espírito Santo & $8.813 .275,67$ & 2,51 \\
$\mathbf{2 3}$ & Ceará & $16.547 .480,06$ & 1,96 \\
$\mathbf{2 4}$ & Minas Gerais & $36.203 .104,86$ & 1,85 \\
$\mathbf{2 5}$ & Maranhão & $11.611 .510,99$ & 1,77 \\
$\mathbf{2 6}$ & Bahia & $24.575 .376,67$ & 1,75 \\
$\mathbf{2 7}$ & São Paulo & $46.033 .784,88$ & 1,12 \\
\hline $\mathbf{D a}$ & & & \\
\hline
\end{tabular}

Nota: Dados disponíveis até 2014

Fonte: Brasil (2018) e IBGE (2010)

A principal reflexão dos dados acerca do repasse do Fundo Nacional de Segurança Pública está na insuficiência dos recursos para o serviço. Com exceção de São Paulo e Rio de Janeiro, os estados com maiores valores, receberam, em média, menos de um real por habitante para cada ano, para investir em segurança pública. Efetivamente, falta ao governo uma maior preocupação com a segurança pública.

A Tabela 3 permite uma análise acerca dos investimentos, por habitante, nas Unidades da Federação, no período entre 2014 e 2015, considerando as informações divulgadas pelo Fórum Brasileiro de Segurança Pública (2016). No ano de 2014, o Acre foi quem mais investiu em segurança pública por habitante, com $\mathrm{R} \$ 612,73$. Além dele, Rondônia, Roraima e Minas Gerais apresentaram valores superiores a $R \$ 500,00$. Em contrapartida, Amapá e Piauí investiram menos de $R \$ 90,00$ com segurança pública, sendo que o Piauí gastou apenas $\mathrm{R} \$ 18,93$ para cada habitante em 2014. Em valores absolutos, Minas Gerais e São Paulo ultrapassaram R\$ 10 bilhões investidos em segurança pública em 2014.

Já em 2015, foi possível constatar que os valores investidos pelos estados aumentaram significativamente. Apenas quatro Unidades da Federação apresentaram redução no investimento em segurança pública. O Amapá foi quem mais investiu em segurança pública por habitante, com $R \$$ 695,52 , em 2015. Além dele, Minas Gerais, Roraima e Rondônia apresentaram valores superiores a $R \$ 600,00$. Em contrapartida, o Piauí foi o único a gastar menos de $R \$ 100,00$ com segurança pública em 2015. Em valores absolutos, realce para Minas Gerais, que investiu $R \$ 13$ bilhões em segurança pública. Quanto à variação no período, o Amapá altíssimo crescimento: 674,5\%; e o Piauí aumentou o investimento em $287,4 \%$. Entre as Unidades da Federação que menos investiram, comparando 2014 e 2015, destaque para o Distrito Federal, com queda de 16,9\%. Esses dados ganham em complexidade - e em possibilidades de reflexão - conforme se associam com as taxas de homicídios. 
Tabela 3: Unidades da Federação. Relação de despesas estaduais com função segurança pública por habitante (R\$/por hab.), 2014 e 2015, e variação no período (\%)

\begin{tabular}{|c|c|c|c|c|}
\hline & Unidade da Federação & 2014 & 2015 & Variação (\%) \\
\hline 01 & Acre & 612,73 & 584,08 & $-4,7$ \\
\hline 02 & Alagoas & 340,73 & 338,99 & $-0,5$ \\
\hline 03 & Amapá & 89,80 & 695,52 & 674,5 \\
\hline 04 & Amazonas & 389,33 & 390,26 & 0,2 \\
\hline 05 & Bahia & 244,68 & 265,23 & 8,4 \\
\hline 06 & Ceará & 201,08 & 214,40 & 6,6 \\
\hline 07 & Distrito Federal & 315,70 & 262,29 & $-16,9$ \\
\hline 08 & Espírito Santo & 343,51 & 354,34 & 3,2 \\
\hline 09 & Goiás & 361,51 & 417,83 & 15,6 \\
\hline 10 & Maranhão & 165,92 & 175,71 & 5,9 \\
\hline 11 & Mato Grosso & 368,90 & 472,04 & 28,0 \\
\hline 12 & Mato Grosso do Sul & 387,55 & 438,72 & 13,2 \\
\hline 13 & Minas Gerais & 514,21 & 664,67 & 29,3 \\
\hline 14 & Pará & 247,99 & 280,27 & 13,0 \\
\hline 15 & Paraíba & 228,61 & 242,08 & 5,9 \\
\hline 16 & Paraná & 240,08 & 315,21 & 31,3 \\
\hline 17 & Pernambuco & 248,33 & 242,55 & $-2,3$ \\
\hline 18 & Piauí & 18,93 & 73,32 & 287,4 \\
\hline 19 & Rio de Janeiro & 482,67 & 543,50 & 12,6 \\
\hline 20 & Rio Grande do Norte & 235,84 & 253,76 & 7,6 \\
\hline 21 & Rio Grande do Sul & 280,90 & 285,93 & 1,8 \\
\hline 22 & Rondônia & 596,06 & 618,99 & 3,8 \\
\hline 23 & Roraima & 542,24 & 664,08 & 22,5 \\
\hline 24 & Santa Catarina & 315,84 & 321,55 & 1,8 \\
\hline 25 & São Paulo & 251,73 & 272,95 & 8,4 \\
\hline 26 & Sergipe & 358,29 & 379,15 & 5,8 \\
\hline 27 & Tocantins & 421,40 & 457,90 & 8,7 \\
\hline
\end{tabular}

Fonte: Adaptado de Fórum Brasileiro de Segurança Pública (2016) e IBGE (2010).

Sobre isso, a Tabela 4 é uma possibilidade de comparação entre os dados de repasse e um elemento da violência: os homicídios. Nela pode ser observado as taxas de homicídios, em grupo de cem mil habitantes, entre 1998 e 2016, além de elementos proporcionais, como a variação, em porcentagem $(\Delta)$ no período, e a variação $(\Delta)$ com relação a posição em 1998 e a posição atual no ranking.

O Estado de Pernambuco foi o que apresentou a maior taxa de homicídios (em 100 mil), em 1998. Porém, em 2016, ele apareceu na sexta posição do ranking. Já Sergipe foi o que exibiu a maior taxa em 2016, com 64,7 homicídios para cada cem mil pessoas, um salto de vinte posições no ranking. Apesar dessa explosão de homicídios, os investimentos em segurança pública em Sergipe aumentaram menos de $6 \%$ e o estado segue sendo um dos que menos recebe repasse do Fundo Nacional de Segurança Pública.

O Pará, que subiu quinze posições - saiu de décimo nono, em 1998, para quarto lugar, em 2016 -, não apresenta valores significativos de recebimento de repasse do Fundo Nacional de Segurança Pública e de investimentos do governo estadual em segurança pública. Isso ajuda a explicar que a ausência de políticas públicas de segurança é um dos fatores influenciadores no aumento de violência no Estado. Fernandes (2017) considera como um dos fatores explicativos para a violencia e para a insegurança objetiva, a ausência ou a insuficiência do Estado enquanto agente principal na promoção da segurança pública. 
Tabela 4: Unidades da Federação: Taxas de homicídios, em 100 mil, na População Total, 1998 a 2016, variação no período (\%)e deslocamento no ranking

\begin{tabular}{|c|c|c|c|c|c|c|c|c|c|c|c|c|c|}
\hline & UF & 98 & 00 & 02 & 04 & 06 & 08 & 10 & 12 & 14 & 16 & $\Delta \%$ & $\Delta \mathbf{R}$ \\
\hline 01 & SE & 10,4 & 23,3 & 29,7 & 24,4 & 29,8 & 28,7 & 32,7 & 41,6 & 49,4 & 64,7 & $522 \%$ & $\uparrow 20$ \\
\hline 02 & $\mathrm{AL}$ & 21,8 & 25,6 & 34,3 & 35,1 & 53,0 & 60,3 & 66,9 & 62,8 & 62,8 & 54,2 & $149 \%$ & $\uparrow 09$ \\
\hline 03 & $\mathrm{RN}$ & 8,5 & 9,0 & 10,6 & 11,7 & 14,8 & 23,2 & 25,6 & 34,8 & 47,0 & 53,4 & $528 \%$ & $\uparrow 21$ \\
\hline 04 & PA & 13,3 & 13,0 & 18,4 & 22,7 & 29,2 & 39,2 & 46,4 & 41,4 & 42,5 & 50,9 & $283 \%$ & $\uparrow 15$ \\
\hline 05 & AP & 38,7 & 32,5 & 35,0 & 31,3 & 33,0 & 34,4 & 38,9 & 36,2 & 34,1 & 48,7 & $26 \%$ & $\uparrow 01$ \\
\hline 06 & PE & 58,9 & 54,0 & 54,8 & 50,7 & 52,7 & 50,7 & 39,5 & 37,3 & 36,2 & 47,3 & $-20 \%$ & $\downarrow 05$ \\
\hline 07 & $B A$ & 9,7 & 9,4 & 13,0 & 16,6 & 23,5 & 32,9 & 41,7 & 43,4 & 40,0 & 46,9 & $384 \%$ & $\uparrow 15$ \\
\hline 08 & GO & 13,4 & 20,2 & 25,5 & 26,4 & 24,6 & 30,0 & 33,0 & 45,4 & 44,3 & 45,3 & $238 \%$ & $\uparrow 10$ \\
\hline 09 & $A C$ & 21,2 & 19,4 & 25,7 & 18,7 & 22,6 & 19,6 & 22,5 & 27,4 & 29,4 & 44,5 & $110 \%$ & $\uparrow 04$ \\
\hline 10 & CE & 13,4 & 16,5 & 18,9 & 20,0 & 21,8 & 24,0 & 31,8 & 44,6 & 52,3 & 40,6 & $203 \%$ & $\uparrow 07$ \\
\hline 11 & $\mathrm{RR}$ & 50,6 & 39,5 & 34,9 & 22,6 & 27,3 & 25,4 & 26,8 & 30,7 & 31,8 & 39,7 & $-22 \%$ & $\downarrow 07$ \\
\hline 12 & RO & 38,3 & 33,8 & 42,3 & 38,0 & 37,7 & 32,1 & 35,0 & 33,0 & 33,1 & 39,3 & $3 \%$ & $\downarrow 05$ \\
\hline 13 & TO & 12,3 & 15,5 & 14,9 & 16,4 & 17,7 & 18,1 & 23,6 & 26,7 & 25,5 & 37,6 & $206 \%$ & $\uparrow 07$ \\
\hline 14 & RJ & 55,3 & 51,0 & 56,5 & 49,2 & 45,8 & 34,0 & 35,4 & 29,4 & 34,7 & 36,4 & $-34 \%$ & $\downarrow 11$ \\
\hline 15 & AM & 21,3 & 19,8 & 17,3 & 16,9 & 21,1 & 24,8 & 31,1 & 37,4 & 32,0 & 36,3 & $70 \%$ & $\downarrow 03$ \\
\hline 16 & MT & 36,3 & 39,8 & 37,0 & 32,1 & 31,5 & 31,8 & 32,0 & 34,5 & 42,1 & 35,7 & $-2 \%$ & $\downarrow 07$ \\
\hline 17 & MA & 5,0 & 6,1 & 9,9 & 11,7 & 15,0 & 19,7 & 23,1 & 26,5 & 35,9 & 34,6 & $592 \%$ & $\uparrow 10$ \\
\hline 18 & PB & 13,5 & 15,1 & 17,4 & 18,6 & 22,6 & 27,3 & 38,6 & 40,0 & 39,3 & 33,9 & $151 \%$ & $\downarrow 02$ \\
\hline 19 & ES & 58,4 & 46,8 & 51,2 & 49,4 & 51,2 & 56,4 & 51,0 & 46,6 & 41,4 & 32,0 & $-45 \%$ & $\downarrow 17$ \\
\hline 20 & RS & 15,3 & 16,3 & 18,3 & 18,5 & 17,9 & 21,8 & 19,5 & 22,1 & 24,3 & 28,6 & $87 \%$ & $\downarrow 05$ \\
\hline 21 & PR & 17,6 & 18,5 & 22,7 & 28,1 & 29,8 & 32,6 & 34,4 & 33,0 & 26,9 & 27,4 & $56 \%$ & $\downarrow 07$ \\
\hline 22 & DF & 37,4 & 37,5 & 34,7 & 36,5 & 32,3 & 34,1 & 30,7 & 36,0 & 29,6 & 25,5 & $-32 \%$ & $\downarrow 14$ \\
\hline 23 & MS & 33,5 & 31,0 & 32,4 & 29,6 & 29,5 & 29,5 & 26,8 & 27,3 & 26,7 & 25,0 & $-25 \%$ & $\downarrow 13$ \\
\hline 24 & MG & 8,6 & 11,5 & 16,2 & 22,6 & 21,3 & 19,5 & 18,6 & 23,0 & 22,8 & 22,0 & $156 \%$ & $\downarrow 01$ \\
\hline 25 & $\mathrm{PI}$ & 5,2 & 8,2 & 10,9 & 11,8 & 14,4 & 12,4 & 13,2 & 16,6 & 22,4 & 21,8 & $319 \%$ & $\uparrow 01$ \\
\hline 26 & SC & 7,9 & 7,9 & 10,3 & 11,1 & 11,0 & 13,0 & 13,2 & 12,9 & 13,5 & 14,2 & $80 \%$ & $\downarrow 01$ \\
\hline 27 & SP & 39,7 & 42,2 & 38,0 & 28,6 & 19,9 & 14,9 & 14,6 & 15,7 & 14,1 & 10,9 & $-73 \%$ & $\downarrow 22$ \\
\hline
\end{tabular}

Nota: $\Delta R$ : variação no ranking de 1998 e 2016

Fonte: Adaptado do Waiselfisz (2010) e Ipea (2018).

No Paraná, a violência cresceu significativamente no período de 1998 a 2008, levando o estado para o nono lugar, subindo cinco posições no ranking. Naquele período, os recursos para a segurança pública não chegavam a vinte milhões de reais (menos de dois reais por habitantes). Após 2010, a taxa de homicídio paranaense passou a cair, atingindo, em 2016, 27,4 homicídios a cada cem mil pessoas. No período, o Paraná aumentou o seu investimento em segurança pública (aumento de $31,3 \%$ ) e passou a ser uma das Unidades da Federação que mais recebeu repasse do Fundo Nacional de Segurança Pública - com mais de cinquenta milhões de reais. São Paulo (-73\%) e Rio de Janeiro (-34\%), diferentemente da sensação criada pelos meios de comunicação, apresentaram significativas reduções nas suas taxas.

Considerando a variação entre 1998 e 2016, o Maranhão (592\%), o Rio Grande do Norte (528\%) e o Sergipe (522\%) apresentaram os maiores aumentos nas taxas de homicídios (em 100 mil). Eles estão entre as Unidades da Federação que menos receberam repasse do Fundo Nacional de Segurança Pública, apresentando, respectivamente, $R \$ 11,6$ milhões ( $R \$ 1,77$ por habitante), $R \$ 11,3$ milhões ( $R$ \$ 3,59 por habitante) e $R \$ 9,2$ milhões ( $R \$ 4,49$ por habitante) para o período de cinco anos. Quanto aos invesimentos estaduais em segurnaça pública, os três apresentaram elevação na comparação entre 2014 e 2015, sendo 7,6\% no Maranhão, 5,9\% no Rio Grande do Norte e 5,8\% no Sergipe. 
Assim, observando as Unidades da Federação que enfrentaram aumento nas taxas de homicídios, é possivel constatar que a violência passou, ao longo do período, a ocorrer em maior incidência em lugares que tiveram poucos repasses do Fundo Nacional de Segurança Pública, como Rio Grande do Norte ( $R \$ 3,59$ por habitante), Alagoas ( $R \$ 2,70$ por habitante), Ceará ( $R \$ 1,96$ por habitante) e Bahia ( $R \$ 1,75$ por habitante). Nos casos de Alagoas, Acre e Pernambuco, o investimento estadual com segurança pública diminuiu entre 2013 e 2014. É uma constatação importante e que precisa ser aprofundada na continuação dos estudos acerca da segurança pública. Já o Amapá enfrentou aumento na taxa de homicídios, mesmo com aumento significativo no investimento estadual com segurança pública - nesse caso, é preciso aguardar os dados dos próximos anos para uma melhor compreensão do fenômeno.

\section{CONSIDERAÇÕES FINAIS}

A segurança é um dos principais temas da agenda pública brasileira. Geralmente, as políticas públicas de segurança ocorrem em interface com as políticas urbanas, gerando, uma necessidade de articulação entre os projetos governamentais. Segurança pública, em síntese, corresponde à segurança do público, da coletividade e dos cidadãos, seja em espaços públicos, como as ruas, praças e estabelecimentos públicos, seja nos espaços privados de residência, trabalho e lazer. No entanto, nem sempre ela apresentou um caráter coletivo e/ou público. Durante boa parte da história, nas sociedades ocidentais, as questões relacionadas à segurança foram de cunho privado, sem cobranças diretas às autoridades governamentais e, por conseguinte, ao Estado. No caso brasileiro, ela ancora-se em um sistema pluralista, porém pouquíssimo articulado.

No Brasil, para a segurança, existem órgãos sob judicie federal, como a polícia federal e a polícia rodoviária federal; sob responsabilidade dos Estados, como polícias civis e polícias militares (incluindo os bombeiros militares); e, no caso dos municípios, podem existir, ainda, as guardas municipais, destinadas à proteção de seus bens, serviços e instalações. Além disso, existe o sistema judicial, com códigos e leis, procedimentos penais e organizações para aplicação. O trâmite é longo e demorado: passa pela polícia militar e civil para poder gerar um inquérito. Depois, chega ao Ministério Público (para tornar o acusado em réu), e "termina" no fórum para os procedimentos de julgamento. Após uma série de instâncias e possibilidades de recursos, o Executivo, por meio das unidades prisionais, faz o encarceramento.

Quanto ao encarceramento, os dados mostram que a população carcerária brasileira triplicou entre 2010 e 2015, chegando a quase 700 mil presos, em 2015, sendo muitos em condição provisória. Por isso, autores vêm estudando o modo de vida dessa parcela da população brasileira, que é potencializada quando se considera os familiares e amigos. Por todo o contexto, as políticas públicas tornaram-se indispensáveis para o cotidiano da sociedade brasileira, seja para quem está livre ou privado de liberdade.

A relativa demora em executar estratégias de segurança pública reflete no Brasil contemporâneo. Apenas no final da década de 1990 é que surgiram as primeiras iniciativas amplas de mudanças. Porém, foram pequenas; elas se limitam a intervencionismos governamentais voltados para soluções paliativas. Além disso, vive-se uma grande defasagem na estrutura física e nos serviços públicos que deveriam garantir a segurança e nos recursos humanos, que atende a população.

No Brasil, a segurança passa pela elite e pelos políticos. Ambos quase sempre exigem e aprovam leis mais duras contra os "bandidos", além de criarem estereótipos dos criminosos e considerá-los irrecuperáveis para o convívio social. Mas, o combate à violência não pode ser por mais violência, sendo inaceitáveis termos como "pagar pelo que fez" e "aprender o que é bom". Por isso, como forma de repudiar e muitas vezes de auto segurança, as pessoas passam, no momento de incerteza, a "negar a violência", a praticar a "lei do silêncio", a romper com a sociabilidade, etc.

Já quanto aos dados apresentados, espera-se que causem inquietações para futuros trabalhos. No Estado com maior taxa de aprisionados, o Mato Grosso do Sul, a taxa de homicídios é a quinta menor do Brasil, o que corrobora o debate teórico acerca do aprisionamento por crimes considerados não violentos. Os Estados de São Paulo e do Rio de Janeiro, grandes receptores de verbas destinadas à segurança pública, tiveram significativas quedas nos indicadores de homicídios no Brasil. No caso paulista, o estado passou a apresentar, em 2016, a menor taxa de homicídio do país, representando uma queda de $73 \%$ em comparação com a taxa de 1998. Aliás, os cinco que mais receberam repasses do Fundo Nacional de Segurança Pública apresentaram queda na taxa de homícidio, inclusive Pernambuco que era líder nesse ranking em 1998.

\begin{tabular}{llllll}
\hline Caminhos de Geografia & Uberlândia - MG & v. 19, n. 67 & Set/2018 & p. 219-233 & Página 231
\end{tabular}


Por isso, o fato de $82 \%$ das Unidades da Federação perderem recursos no período de 2013 a 2014 (oito não receberam repasse algum) deve ser visto com preocupação. Sergipe e Alagoas, que apresentaram as maiores taxas de homicídios (em 100 mil), em 2016, estão entre os que menos recebem repasse do Fundo e entre os que menos investem, considerando a relação recurso/habitantes, em segurança pública. Os casos do Acre, Amapá, Pará, Paraná e Pernambuco também são instigantes e precisam de estudos mais aprofundados. O Paraná, por exemplo, vivenciou um aumento de violência no período de 1998 a 2008, levando-o para o nono lugar no ranking, sendo que seus recursos em segurança pública não passavam dos vinte milhões de reais para um período de cinco anos (menos de dois reais por habitante para o período), e, depois, com o aumento do repasse do Fundo Nacional de Segurança Pública e do investimento estadual em segurança, vivenciou uma queda na taxa de homicídio. Minas Gerais, que tem a quarta menor taxa de homicídio do Brasil, é um dos que mais investem em segurança pública, sendo que em 2015 passou de $R \$ 13$ bilhões investidos no setor.

Logo, é necessário que se pense e pratique uma efetiva articulação entre a prevenção e a segurança para que as políticas nacionais, regionais e locais, quanto à segurança, não resultem em mais segregação, aumento da violência e do sentimento de insegurança em todos os espaços e na população em sua totalidade.

\section{REFERÊNCIAS}

BAUMAN, Zygmunt. Comunidade: a busca por segurança no mundo atual. Tradução de Plínio Dentzien. Rio de Janeiro: Zahar, 2003.

Tempos líquidos. Tradução de Carlos Alberto Medeiros. Rio de Janeiro: Zahar, 2007.

BENEVIDES, Maria Victoria. Violência, povo e política. São Paulo: CEDEC/Brasiliense, 1983.

BRASIL. Constituição da República Federativa do Brasil: promulgada em 5 de outubro de 1988. 18ª edição. São Paulo: Saraiva, 1998.

BRASIL. Ministério da Justiça: Departamento Penitenciário Nacional. Levantamento Nacional de Informações Penitenciárias. 2014. Disponível em: http://www.justica.gov.br/seus-direitos/politicapenal/documentos/infopen_dez14.pdf acesso em: 28 de maio de 2018.

. Ministério da Justiça: Departamento Penitenciário Nacional. Levantamento Nacional de Informações Penitenciárias 2015. 2017. Disponível em: <www.justica.gov.br/relatorio_2015_dezembro.pdf> acesso em: 16 de agosto de 2018.

Ministério da Justiça: Sistema penal. 2011. Disponível em:

<http://portal.mj.gov.br/data/Pages/MJD574E9CEITEMID364AC56ADE924046B46C6B9CC447B586P TBRNN.htm > acesso em: 15 de maio de 2011.

BRASIL, Portal da Transparência. Convênios. Levantamento do órgão 30911 - Fundo Nacional de Segurança Pública. 2018. Disponível em: <http://www3.transparencia.gov.br/convenios/> acesso em: 18 de agosto de 2018.

BRASIL. Subchefia para assuntos jurídicos: Lei no 7.209 , de 11 de julho de 1984. 1984. Disponível em: <http://www.planalto.gov.br/ccivil/LEIS/1980-1988/L7209.htm> acesso em: 05 de maio de 2011.

Subchefia para assuntos jurídicos: Lei oㅜ 9.099, de 26 de setembro de 1995. 1995. Disponível em: <http://www.planalto.gov.br/ccivil_03/leis/L9099.htm> acesso em: 05 de maio de 2011.

ENDLICH, Angela Maria. FERNANDES, Pedro Henrique Carnevalli Fernandes. Aumento da violência em pequenas cidades, sentimento de insegurança e controle social. Scripta Nova (Barcelona), v. XVIII, p. 1-20, 2014.

FERNANDES, Pedro Henrique Carnevalli Fernandes. Um espectro ronda as pequenas cidades: 0 aumento da violência e da insegurança objetiva. Tese (doutorado) - Universidade Estadual de Maringá, Programa de Pós-Graduação em Geografia, 2017, 525p;

FÓRUM BRASILEIRO DE SEGURANÇA PÚBLICA. Anuário brasileiro de segurança pública. 2016. Disponível em: <http://www.forumseguranca.org.br/publicacoes/10o-anuario-brasileiro-deseguranca-publica/> acesso em 18 de agosto de 2018. 
GAVIRIA M., Margarita Rosa. Controle social expresso em representações sociais de violência, insegurança e medo. Sociologias, Porto Alegre, n. 20, p. 72 a 107, jul./dez., 2008.

GOES, Eda Maria. A recusa das grades: rebeliões nos presídios paulistas: 1982-1986. 1ed. São Paulo: IBCCRIM, 2009. 2004. Transição política e cotidiano penitenciário. In: História, Franca, v. 23, n.1-2, p. 219-238,

IBGE, Instituto Brasileiro de Geografia e Estatística. Censo 2010. 2010. Disponível em: <https://censo2010.ibge.gov.br/acesso> em: 28 de maio de 2018.

IPEA, Instituto de Pesquisa Econômica Aplicada. Atlas da Violência. 2010 - 2016. Disponível em: <http://www.ipea.gov.br/atlasviolencia/> acesso em: 18 de agosto de 2018.

NEME, Cristina. Violência e segurança: um olhar sobre a França e o Brasil. In: Rev. Sociol. Polit. [online], n.25, p. 123-137, 2005.

PEDRAZZINI, Yves. A violência das cidades. Tradução de Giselle Unti. Petrópolis (RJ): Vozes, 2006.

SAPORI, Luís Flávio. Segurança pública no Brasil: desafios e perspectivas. Rio de Janeiro: Editora FGV, 2007.

SILVA, Luiz Antônio Machado da. Sociabilidade violenta: por uma interpretação da criminalidade contemporânea no Brasil urbano. Sociedade e Estado, Brasília, v. 19, n. 1, p. 53-84, jan./jun., 2004.

SOUZA, Marcelo Lopes de. Fobópole: o medo generalizado e a militarização da questão urbana. Rio de Janeiro, Bertrand Brasil, 2008.

WAISELFISZ, Julio Jacobo. Mapa da Violência 2010: anatomia dos homicídios no Brasil. São Paulo: Instituto Sangari, 2010.

Recebido em: 22/07/2017

Aceito para publicação em: 29/08/2018 